\title{
Epoxy-Carbazole Polymeric Network Nanolayers for Organic Light-Emitting Devices
}

\author{
Jin-Woo Park, ${ }^{1}$ Eung-Kyoo Lee, ${ }^{1}$ Myon Cheon Choi, ${ }^{1}$ Hwajeong Kim, ${ }^{1,2}$ Jihwan Keum, ${ }^{1,3}$ \\ Chang-Sik $\mathrm{Ha}^{1}$ and Youngkyoo Kim ${ }^{4}$ \\ ${ }^{1}$ Department of Polymer Science and Engineering, Pusan National University, Busan 609-735, South Korea \\ ${ }^{2}$ Institute of Biomedical Engineering, Imperial College London, Exhibition Road, London SW7 2AZ, UK \\ ${ }^{3}$ Samsung SDI Co. Ltd., 818 Gacheon-Ri, Samnam-Myeon, Ulju-Gu, Ulsan 689-701, South Korea \\ ${ }^{4}$ Experimental Solid State Physics Group, Blackett Laboratory, Department of Physics, \\ Imperial College London, Prince Consort Road, London SW7 2BW, UK
}

Received 24 March 2006; Revised 5 August 2006; Accepted 24 October 2006

\begin{abstract}
We report the study of epoxy-carbazole polymeric network (ECzPN) nanolayers as a hole injection/transport layer in organic light-emitting devices. The ECzPN nanolayers were prepared by the thermal curing reaction of epoxidized cresol novolak and 3,6diaminocarbazole in the presence of catalytic amount of triphenyl phosphine. The curing reaction was examined with Fourier transformed infrared spectroscopy, whilst the thermal stability was studied with thermogravimetric analysis. Optical absorption and emission spectroscopy were employed to investigate the optical properties of ECzPN nanolayers, whilst atomic force microscopy was used to examine the surface nanomorphology of ECzPN nanolayers. The result showed that the device performance was greatly influenced by the weight ratio of monomers, because the highest occupied molecular orbital level of ECzPN was significantly changed with the ratio. This is attributed to the ground-state complexes induced by the specific interaction (hydrogen bonding) between the lone pair electrons in amines of carbazole moieties and the hydroxyl group of ring-opened epoxide moieties.
\end{abstract}

Copyright (c) 2006 Jin-Woo Park et al. This is an open access article distributed under the Creative Commons Attribution License, which permits unrestricted use, distribution, and reproduction in any medium, provided the original work is properly cited.

\section{INTRODUCTION}

Organic light-emitting devices (OLED) have attracted great attention for flat-panel-display (FPD) applications due to their sophisticated device structure that is simpler than liquid crystal displays (LCDs) as well as their fast response time and wide viewing angle which are similar to typical cathode ray tube (CRT) [1]. These features still lure FPD manufactures to consider OLED as one of the next generation's digital television candidates, even though some obstacles including unsatisfied lifetime and lower device efficiency have been recently issued by the concentrated research and development for a couple of decades [2]. Of these obstacles the short device lifetime can be mainly attributed to the inherent instability of organic nanolayers in devices, which is much prominent for small molecule-based OLEDs. Although one of the factors leading to the instability could be sorted out by applying the accelerated preoxidation method [2], all the factors could not be overcome at the moment when it comes to the fundamental aspect of organic nanolayers, particularly based on small molecules.
This problem has motivated the development of molecularly doped polymer films based on thermally stable polymers as well as functional polymer films for hole injection and/or transport layer, since each monomer in polymers, whether they are linked via covalent bonds or strongly bound in stable polymer host, could be more stabilized in polymers than in individual small molecules [3-11]. For instance, we have introduced a semiconducting polyimide (SPI) nanolayer as a hole injection/transport layer for OLEDs, which resulted in a remarkably extended device lifetime [12]. This improved reliability is undoubtedly ascribed to the excellent thermal stability of SPI nanolayers due to the high glass transition temperature $\left(\mathrm{Tg}=220^{\circ} \mathrm{C}\right)$ of SPI $[13,14]$.

With similar concept, we made a chemically cross-linked epoxy network nanolayer doped with hole-transporting molecules as a hole injection/transport layer for durable OLEDs [15]. This pioneering work shed a light on a possibility of using epoxy network nanolayers for OLEDs, because cross-linked epoxy networks are insoluble in common organic solvents and show very excellent thermal stability due 
to their three-dimensional network structure [15]. Because in the previous work the hole-transporting molecules were dispersed in the chemically cross-linked epoxy network made of epoxidized cresol novolak (ECN) and phenolic novolak in which both are electronically/electrically insulating, however, heavy loading of hole-transporting molecules to obtain a good hole-transporting property resulted in large-scale phase segregation.

In this work, we have attempted to make chemically cross-linked epoxy networks using ECN and functionalized carbazole moiety, without any inclusion of hole-transporting components, because the carbazole moiety is electronically active so that it is expected to play a hole-transporting role, considering previous uses of several carbazole moieties in organic photorefractive devices, OLEDs, and solar cells [1618]. The result showed that controlling the monomer ratio between ECN and carbazole moiety led to a uniform epoxycarbazole polymer network (ECzPN) nanolayer that exhibits no phase segregation at all. At this monomer ratio, the improved device performance has been achieved, which is similar to the performance of well-known standard OLED based on $N, N^{\prime}$-diphenyl- $N, N^{\prime}$-bis(3-methylphenyl)-1,1-biphenyl$4,4^{\prime}$-diamine (TPD).

\section{EXPERIMENTAL}

\subsection{Materials}

Epoxidized cresol novolak (ECN, molecular weight = 17 523) was supplied from Kukdo Chemical Co. and was further purified by recrystallization from $n$-hexane/ethanol [90: $10(\mathrm{v} / \mathrm{v})]$ followed by drying in a vacuum at $80^{\circ} \mathrm{C}$ for 24 hours. 3,6-diaminocarbazole (DACz), tris (8-hydroxyquinolinato)aluminum $\left(\mathrm{Alq}_{3}\right)$, and $\mathrm{TPD}$ were purchased from Tokyo Kasei Kogyo Co., Ltd. and used without further purification. Triphenyl phosphine (TPP), a catalyst for epoxy cross-linking reaction, was used as received from Junsei Chemical Co., Ltd. $N, N^{\prime}$-dimethylacetamide (DMAc) was purchased from Aldrich Chemical Co. Figure 1 shows the chemical structure of ECN, DACz, and TPP.

\subsection{Preparation of epoxy-carbazole polymeric network nanolayers and devices}

For preparing epoxy-carbazole polymeric network (ECzPN), a mixture solution of ECN, DACz, and TPP was made using DMAc (solvent) at the solid concentration of $10 \mathrm{wt} \%$ and was vigorously stirred to well mixing. Three different weight ratios $(1.5: 1,2: 1$, and $3: 1)$ of ECN to DACz were employed to investigate the influence of composition. Then these solutions were refluxed at $170^{\circ} \mathrm{C}$ for 1 hour to make a partially reacted (precured) ECzPN for securing a viscous solution suitable for spin-coating. These viscous solutions were spin coated onto various substrates for further characterization, and then finally postcured at the same condition in a vacuum oven.

For the fabrication of OLEDs, indium-tin oxide (ITO) coated glass substrates were patterned in a strip (ITO) size

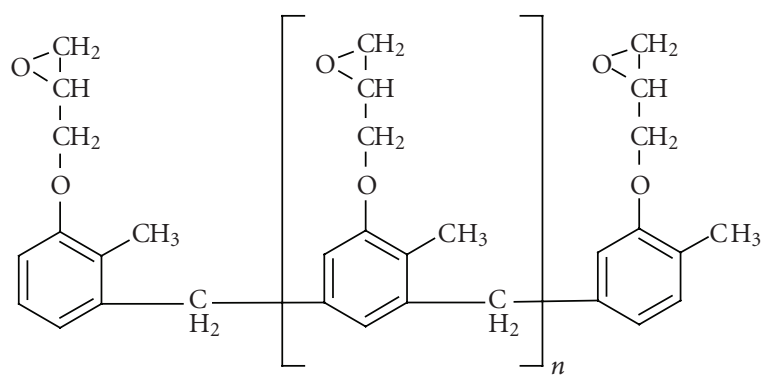

(a)

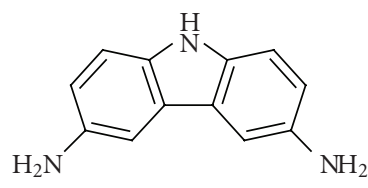

(b)

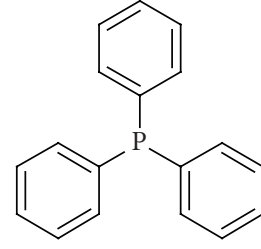

(c)
Figure 1: Chemical structure of materials used for the preparation of epoxy-carbazole polymeric networks (ECzPN): (a) ECN, (b) DACz, and (c) TPP.

of $2 \mathrm{~mm} \times 30 \mathrm{~mm}$ and then were precleaned ultrasonically in deionized water using a nonphosphorus detergent followed by washing in ethanol before drying. The viscous ECzPN solution was spin-coated onto the precleaned ITO coated glass at $4000 \mathrm{rpm}$ for 60 seconds and then soft-baked at $100^{\circ} \mathrm{C}$ for 5 hours in a vacuum oven. Finally, the ECzPN nanolayers (thickness $=60 \mathrm{~nm}$ ) were made by further thermal curing at $170^{\circ} \mathrm{C}$ for 1 hour in a vacuum oven, which were insoluble in DMAc. On top of these ECzPN nanolayers, a $60 \mathrm{~nm}$ thick $\mathrm{Alq}_{3}$ layer was deposited as an emission layer (EML) followed by evaporating the aluminum $(\mathrm{Al})$ cathode in a vacuum of $\sim 5 \times 10^{-6}$ Torr, defining the active emission area of $4 \mathrm{~mm}^{2}$. The control device was also prepared by replacing the ECzPN nanolayer with the $60 \mathrm{~nm}$ thick TPD layer (see Figure 2) which was directly deposited onto the ITO substrate as a deposition rate of $0.5 \sim 1 \mathrm{~nm} / \mathrm{s}$.

\subsection{Measurements of films and devices}

The chemical cross-linking reaction of nanolayers (films) was monitored using an attenuated total reflection (ZnSe crystal) Fourier transform infrared spectrophotometer (ATR FT-IR 460 plus, JASCO Inc.), whilst the thermal degradation was examined using a thermogravimetric analyzer (TGA Q50, TA Instruments Inc.) under a nitrogen environment at a heating rate of $10^{\circ} \mathrm{C} / \mathrm{min}$. The optical absorption spectra of ECzPN nanolayers were measured using a UV-visible spectrophotometer (UV 2010, HITACH), while corresponding photoluminescence (PL) spectra were measured using a fluorescence spectrophotometer (F4500, HITACH). Cyclic voltammetry $(\mathrm{CV})$ measurements were performed using an electrochemical instrument (WPG100, WonATech Co.): Pt and $\mathrm{Ag} / \mathrm{Ag}^{+}$were used as counter and reference electrodes, 

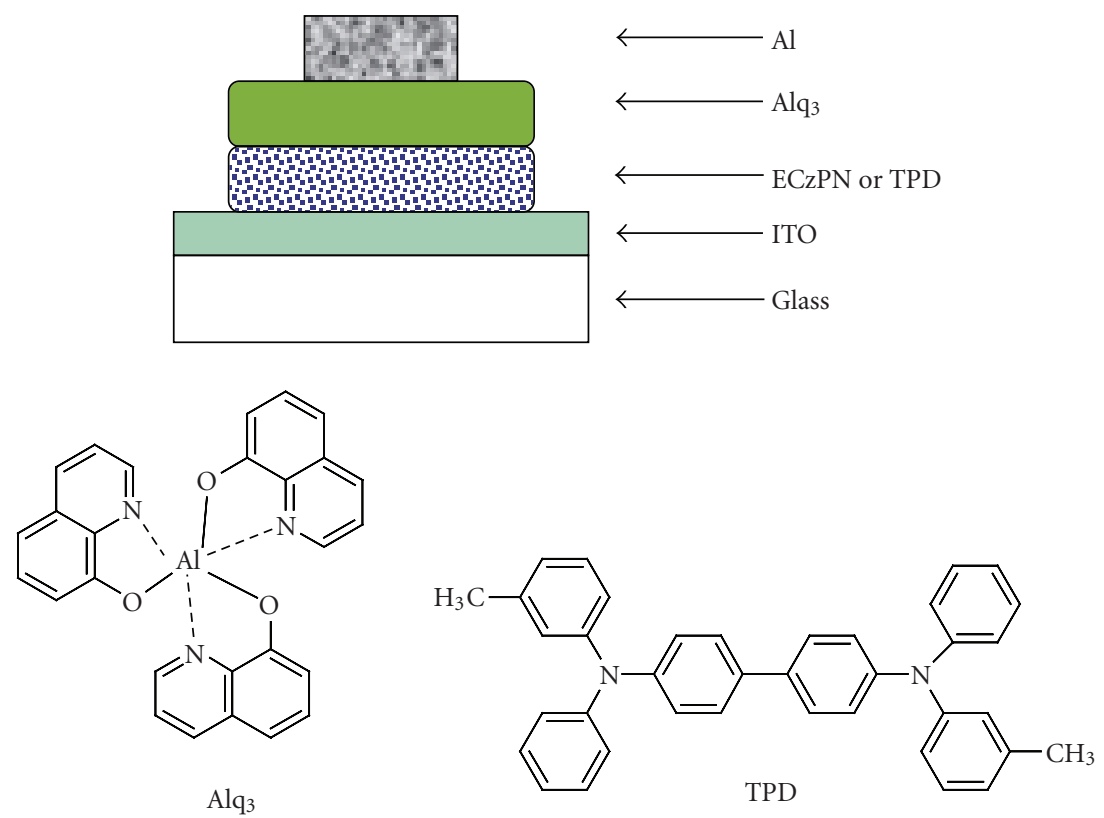

FIgURE 2: Schematic cross-sectional structure of OLED used in this study and chemical structure of $\mathrm{Alq}_{3}$ and TPD.

respectively, whilst $0.1 \mathrm{M}$ TBAP(Tetra- $n$-buthylammonium perchlorate) $/ \mathrm{CH}_{3} \mathrm{CN}$ was employed as a supporting electrolyte solution. The highest occupied molecular orbital (HOMO) of films was calculated using the oxidation onset potential and the work function $(4.8 \mathrm{eV})$ of $\mathrm{Ag}$ electrode (calibrated to the standard $\mathrm{Fc} / \mathrm{Fc}^{+}$redox system) [19]. The surface nanomorphology of TPD and ECzPN nanolayers was measured in air using an atomic force microscope (Nanoscope IIIa, Digital Instrument Co.). The scan area was $5 \mu \mathrm{m} \times 5 \mu \mathrm{m}$ and a tapping mode (scan rate $=1.969 \mathrm{~Hz}$; set point $=1.447-1.46 \mathrm{~V}$ ) was applied to avoid any damage of nanolayer surface upon scanning. We note that the surface images could be slightly deformed because of the possible exposure to moist air during measurements.

The current density-voltage-luminance (J-V-L) characteristics of OLEDs were measured using a customized device measurement system equipped with a photomultiplier tube (PMT, Hamamatsu Photonics Co.) and an electrometer (Keithley 6517). All devices were mounted in a dark sample chamber for the J-V-L measurements in order to get rid of any influence of ambient light.

\section{RESULTS AND DISCUSSION}

\subsection{Characterization for curing reaction and thermal stability}

The curing reaction between $\mathrm{ECN}$ and $\mathrm{DACz}$ (e.g., weight ratio $=3: 1$ ) was characterized with FT-IR spectroscopy. As shown in Figure 3, ECN shows no characteristic peaks in the high wavenumber region over $3000 \mathrm{~cm}^{-1}$ (see Figure 3(a)), whereas DACz exhibits strong secondary amine $\left(\mathrm{NH}, 3390 \mathrm{~cm}^{-1}\right)$ and primary amine $\left(\mathrm{NH}_{2}, 3280 \mathrm{~cm}^{-1}\right.$ and $3180 \mathrm{~cm}^{-1}$ ) peaks at this range (see Figure $3(\mathrm{~b})$ ). In addition,

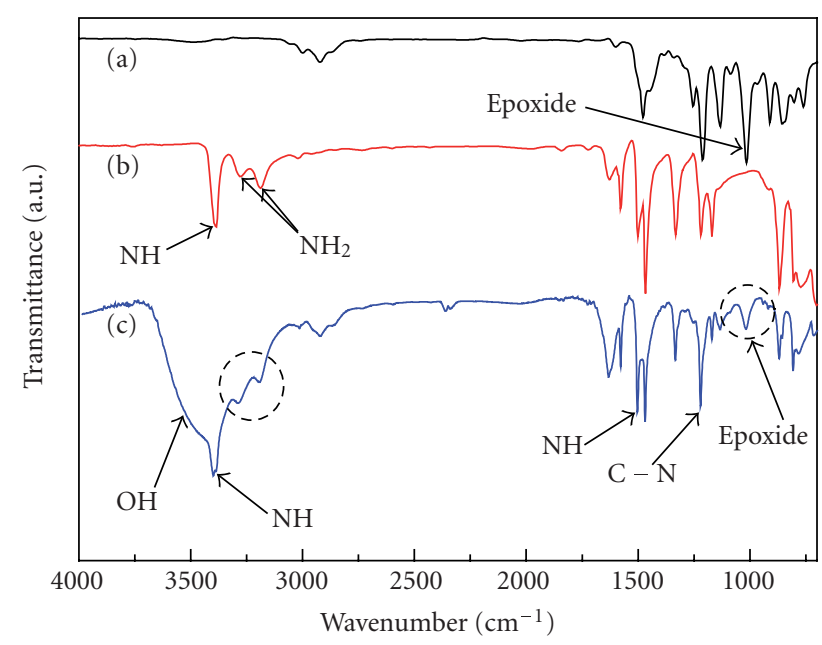

Figure 3: FT-IR spectra of (a) ECN, (b) DACz, and (c) ECzPN $(3: 1)$. The dotted circles point out the remaining monomer materials.

the epoxide peak of ECN is found at $1015 \mathrm{~cm}^{-1}$ which is not observed for DACz. After curing reaction, the broad and huge shoulder at around $3700-3430 \mathrm{~cm}^{-1}$ was measured for ECzPN (see Figure 3(c)), which is attributed to the formation of hydroxyl groups by the ring opening reaction of epoxide ring in ECN (see Figure 4(a) for the reaction mechanism). In the same sense, the peak intensity of epoxide rings at $1015 \mathrm{~cm}^{-1}$ was remarkably reduced for the ECzPN film. Therefore, this basically evidences the occurrence of reaction between $\mathrm{ECN}$ and $\mathrm{DACz}$ to make a three dimensional polymeric network, namely ECzPN here. In addition, the C-N single covalent bond formation between the aliphatic carbon 


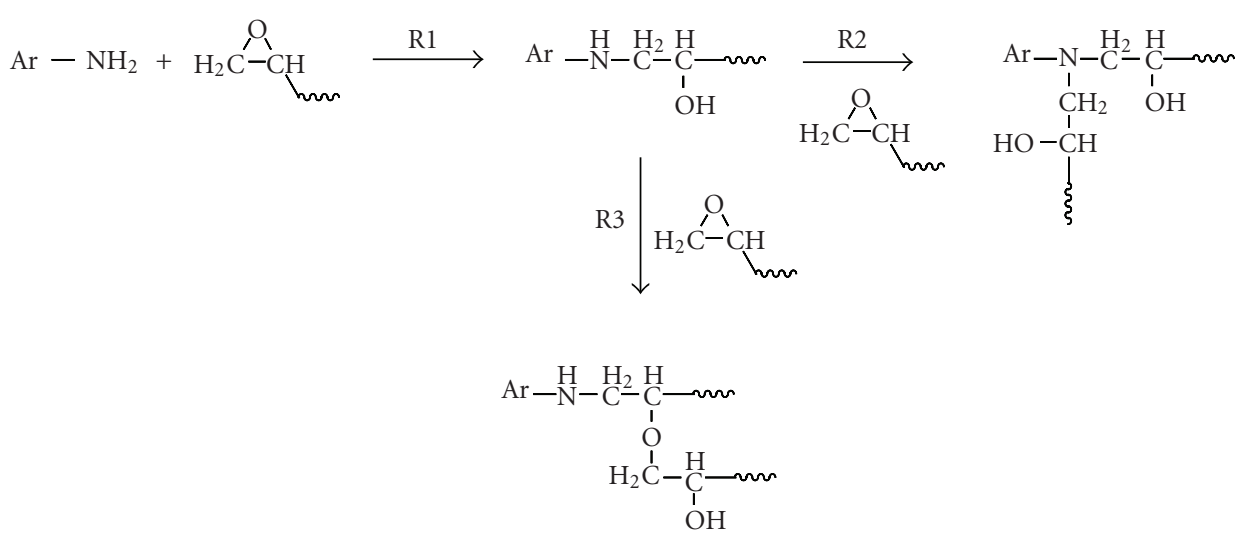

(a)

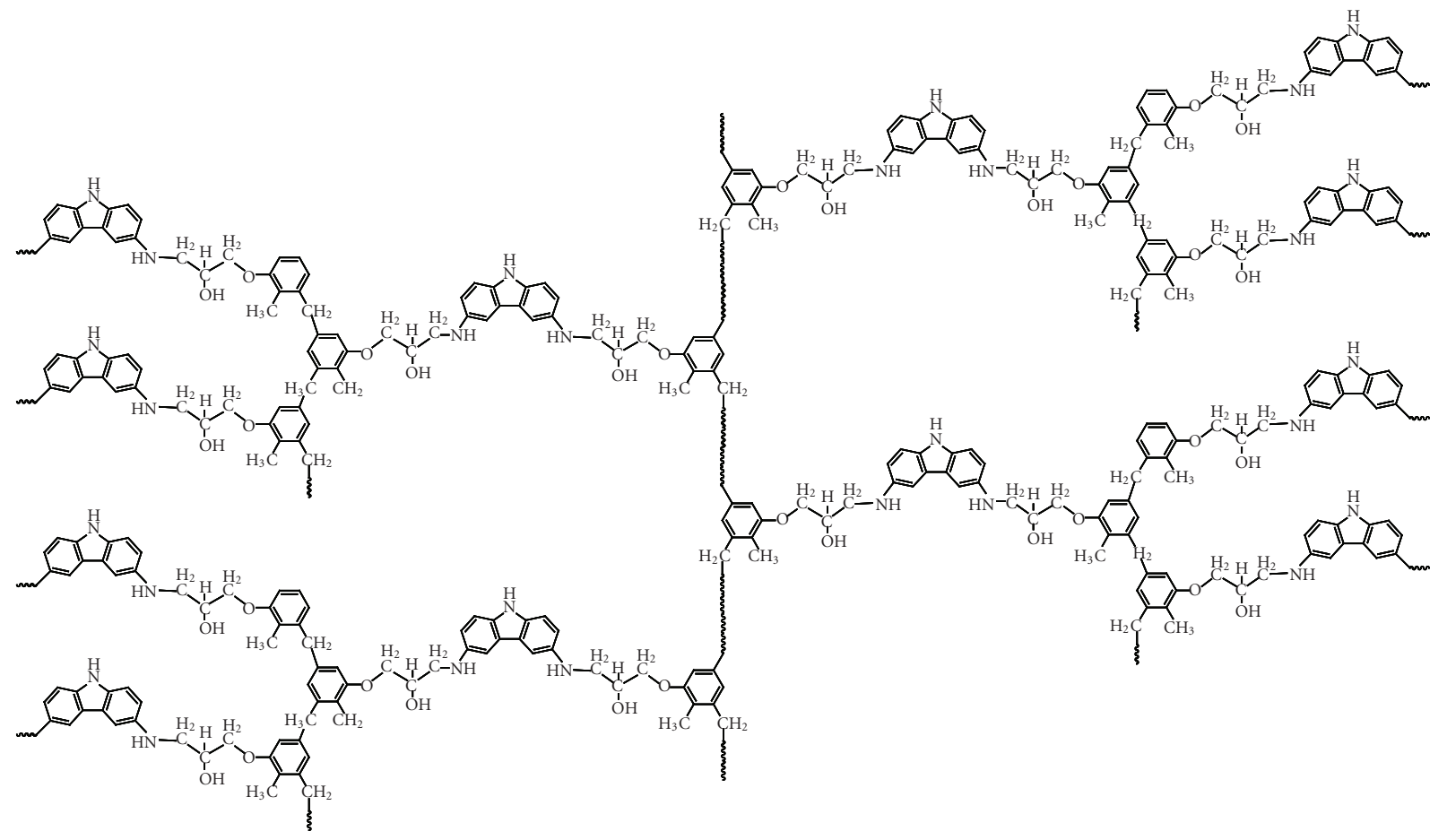

(b)

FIgURe 4: (a) Reaction steps between ECN and DACz to make the epoxy-carbazole polymeric networks: R1 denotes the epoxy ring opening reaction step, whilst R2 and R3 represent the successive curing steps; (b) expected three-dimensional cross-linking structure for ECzPN made in this work.

$\left(\mathrm{CH}_{2}\right)$ of ECN and the secondary amine $\left(\mathrm{NH}_{2}\right)$ of $\mathrm{DACz}$ is identified from the increased intensity of $\mathrm{C}-\mathrm{N}$ stretching and secondary (out-of-plane) $\mathrm{NH}$ peaks at $1220 \mathrm{~cm}^{-1}$ and $1503 \mathrm{~cm}^{-1}$, respectively.

However, considering still existence of $\mathrm{NH}_{2}\left(3280 \mathrm{~cm}^{-1}\right.$ and $\left.3180 \mathrm{~cm}^{-1}\right)$ and epoxide $\left(1015 \mathrm{~cm}^{-1}\right)$ peaks (see dotted circles in Figure 3(c)), the reaction is considered to be incomplete due to the saturation of three-dimensional geometry which hinders moving of two chemicals (ECN and $\mathrm{DACz})$ for further physical contact leading to chemical reaction between two functional groups (epoxide and $\mathrm{NH}_{2}$ ). In addition, because no clear clues were found for the further reactions (R2 and R3 steps in Figure 4(a)), we assume that the dominant reaction here is limited to the R1 step in Figure 4(a). Based on this stage of reaction, the three-dimensional polymeric network (ECzPN) is considered to be made like the schematic drawing as shown in Figure 4(b).

Figure 5 shows the weight loss (thermal degradation) as a function of temperature for ECzPN and starting materials (ECN and DACz). Obviously, DACz exhibits very quick 
weight loss between $250^{\circ} \mathrm{C}$ and $330^{\circ} \mathrm{C}$ and at last only $5 \mathrm{wt} \%$ remain above this temperature. This indicates the thermally unstable nature of functional (hole-transporting) materials like DACz. In contrast, ECN shows relatively quite stable trend. In particular, further improvement in thermal stability is observed for the ECzPN film (3 : 1 weight ratio), which is mainly ascribed to the formation of covalent bond to bind the thermally unstable component (DACz) in the threedimensional network structure. In this context of improved thermal stability against degradation and three-dimensional network formation, we expect the ECzPN film to have a high glass transition temperature though this still needs to be verified by actual measurements.

\subsection{Optical properties}

As shown in Figure 6, the unreacted mixture of ECN and $\mathrm{DACz}(3: 1)$ shows an onset absorption wavelength of $\sim 430 \mathrm{~nm}(2.9 \mathrm{eV})$, which is mainly assigned to the lowest unoccupied molecular orbital (LUMO) of DACz in the mixture film. Surprisingly, new absorption peaks are observed in the wavelengths of $430-600 \mathrm{~nm}$ for the reacted (cured) ECzPN nanolayers (films) (also note the increased intensity at around $350 \mathrm{~nm}$ and $400-425 \mathrm{~nm}$ ). This is considered as a ground-state complex made by the specific interaction (hydrogen bonding) between the lone pair electrons of nitrogen atoms in DACz and the hydroxyl groups of ring-opened epoxide unit of ECN upon the curing reaction (see inset to Figure 6). Here two different resonance states of nitrogen atoms in DACz could result in different complexes (a and b) peaking at $470 \mathrm{~nm}$ (a) and $520 \mathrm{~nm}$ (b). As a consequence, the ECzPN nanolayers have two LUMO bands: major LUMO band from original $\mathrm{DACz}$ singlet (onset = $430 \mathrm{~nm}, 2.9 \mathrm{eV})$, sub-LUMO band from these complexes (onset $=600 \mathrm{~nm}, 2.1 \mathrm{eV}$ ). In particular, it is noted that these complexes are pronounced as the ECN content increases. This indicates that the hydroxyl group concentration plays a critical role in forming the ground-state complexes.

Due to these ground-state complexes made in the ECzPN nanolayers, the photoluminescence spectra also show two major emission peaks at around $450 \mathrm{~nm}$ and $610 \mathrm{~nm}$ : the former is assigned to the singlet transition of $\mathrm{DACz}$, the latter is considered to be a transition for the two complexes (see Figure 7). The intensity of complex peaks increases with the ECN contents, which is in consistent with the absorption spectral trend. Here we note that the very small peak at around $600 \mathrm{~nm}$ was also measured for the unreacted mixture film, which is considered as the marginal formation of complexes even in the unreacted mixture film though it is unclear at the moment whether owing to the hydrogen bonding or not. In particular, the width of major peak at $450 \mathrm{~nm}$ is wider for the ECzPN nanolayers than the unreacted mixture film (also note additional peaks below $400 \mathrm{~nm}$ and shoulders at around $500 \mathrm{~nm}$ ). This result may infer the increased delocalization of electrons in the carbazole ring of DACz owing to the specific interaction leading to the ground-state complex formation.

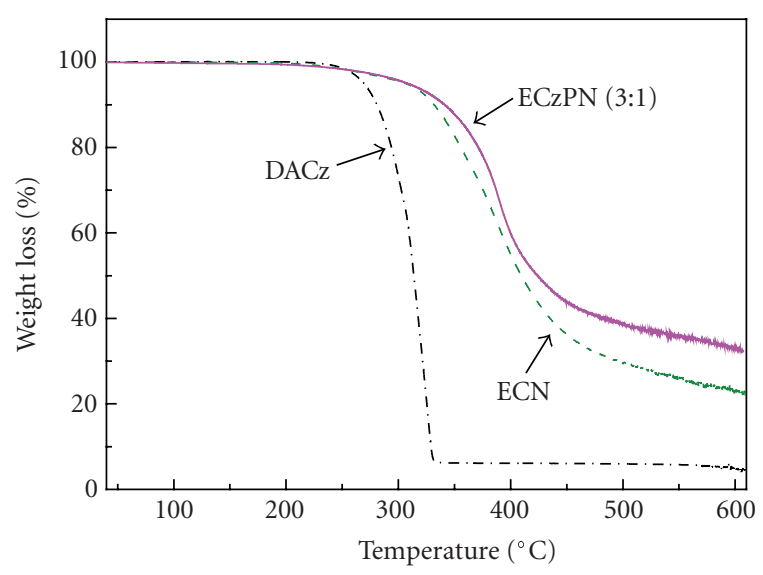

FIgure 5: TGA thermograms for ECN, DACz, and ECzPN. The scan rate was $10^{\circ} \mathrm{C} / \mathrm{min}$.

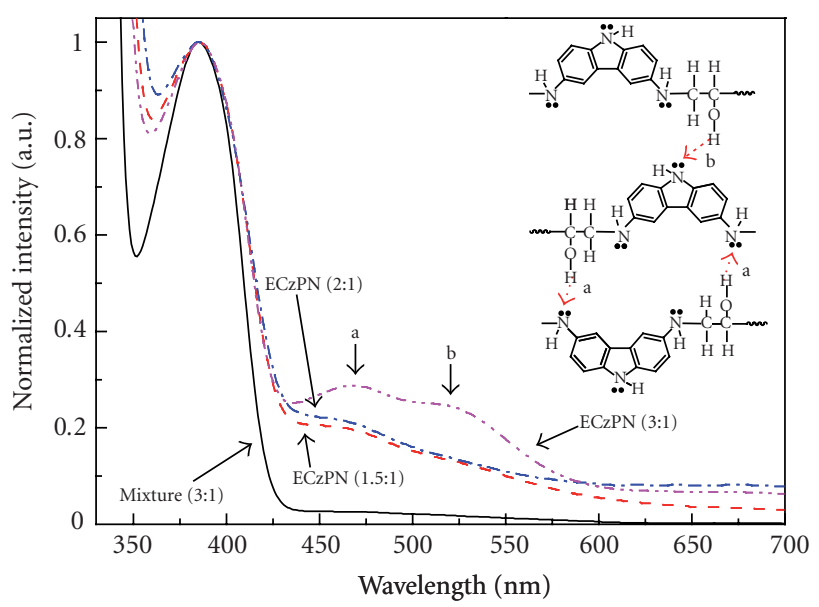

FIGURE 6: Optical absorption spectra of unreacted mixture $(3: 1)$, $\operatorname{ECzPN}(1.5: 1), \operatorname{ECzPN}(2: 1)$, and ECzPN $(3: 1)$. "a" and "b" denote the absorption peaks of complexes formed in the ECzPN nanolayers (see inset for the specific interaction by hydrogen bonding). Here we note that the unreacted mixture showed nearly solidstate film after spin coating but we expect that the internal phase might be gel-like because this film was not fully cross-linked.

\subsection{Characteristics of OLEDs and nanomorphology}

As shown in Figure 8(a), the device made with the ECzPN $(2: 1)$ nanolayer exhibits almost similar J-V shape to the TPD device below the current density of $100 \mathrm{~mA} / \mathrm{cm}^{2}$. However, the devices made with the ECzPN nanolayers at the $(1.5: 1)$ and $(3: 1)$ weight ratios of ECN to DACz showed much higher charge injection/transport voltages. The result for the $(3: 1)$ ratio is acceptable because of the low holetransporting DACz contents, but that for the $(1.5: 1)$ ratio is not a normal case because the hole-transporting characteristics should be improved by increasing the content of holetransporting moiety (DACz). To understand this, we have measured the HOMO level (or ionization potential) of films 


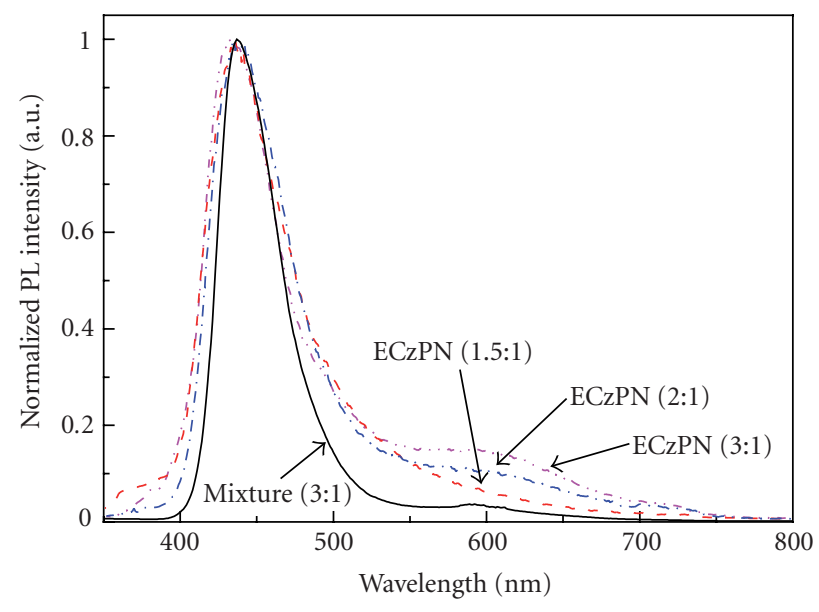

FIgURe 7: Photoluminescence spectra of unreacted mixture $(3: 1)$, $\operatorname{ECzPN}(1.5: 1), \operatorname{ECzPN}(2: 1)$, and $\operatorname{ECzPN}(3: 1)$.

using a cyclic voltammetry (see Figure $9(\mathrm{a})-9(\mathrm{~d})$ ), which resulted in $6.0 \mathrm{eV}, 5.3 \mathrm{eV}$, and $4.6 \mathrm{eV}$ for $(1.5: 1),(2: 1)$, and $(3: 1)$ weight ratios, respectively (see Figure $9(\mathrm{e})-9$ (h) for the flat-energy-band diagrams built by taking into account the complex states as well). This very huge change in HOMO level might be attributed to the role of the specific interaction leading to the formation of complexes. In other words, the measured HOMO level is not solely originated from the pristine $\mathrm{DACz}$ or ECN components but is significantly affected by the lone pair electrons in the complexes which are expected to be more easily extracted as we have previously proposed the similar activation effect between lone pair electrons in nitrogen atoms and carbonyl dipoles in imide groups [12]. In more detail, although for the ECN film with TPP (1 $\mathrm{wt} \%$ ) without $\mathrm{DACz}$ the oxidation onset is observed at $1.3 \mathrm{~V}$ leading to the HOMO level of $6.1 \mathrm{eV}$ (see Figure 9(d)), the $(3: 1)$ ECzPN film shows a very different oxidation onset at $-0.2 \mathrm{~V}$ in the presence of the onset peak at around $1.1 \mathrm{~V}$ which might be related to the oxidation of ECN components (see Figure 9(c)). This evidences the presence of specific interaction leading to making the ground-state complexes as discussed in Figures 6 and 7. Therefore, this HOMO level trend clearly indicates that the hole injection from ITO to the ECzPN layer limits the performance of the $(1.5: 1)$ device owing to the large barrier height, even though the high loading (content) of $\mathrm{DACz}$ could just help to improve the hole transport inside the ECzPN nanolayer.

In particular, the $(1.5: 1)$ device shows much slower increase in the luminance than the current density as the applied voltage increases, whereas other devices show similar increasing trend for luminance and current density (see Figures $8(\mathrm{~b})$ and $8(\mathrm{c})$ ). This huge imbalance (high current but low luminance) of the $(1.5: 1)$ device is attributed to the large electron leakage through the sub-LUMO level (gap) of complexes $(3.9 \mathrm{eV})$ as seen in Figure 9(f). It is worthy to note that the band structure of the ECzPN $(2: 1)$ nanolayer, which resulted in the best device performance amongst the devices with ECzPN nanolayers, is very similar to that of TPD.

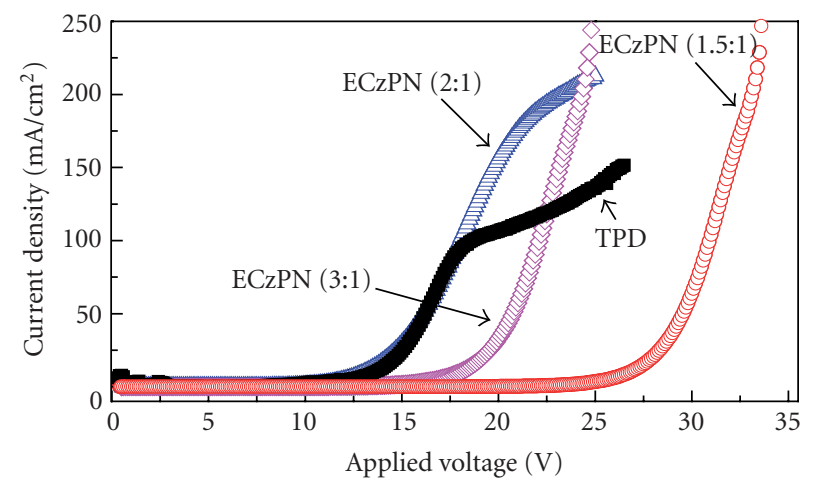

(a)

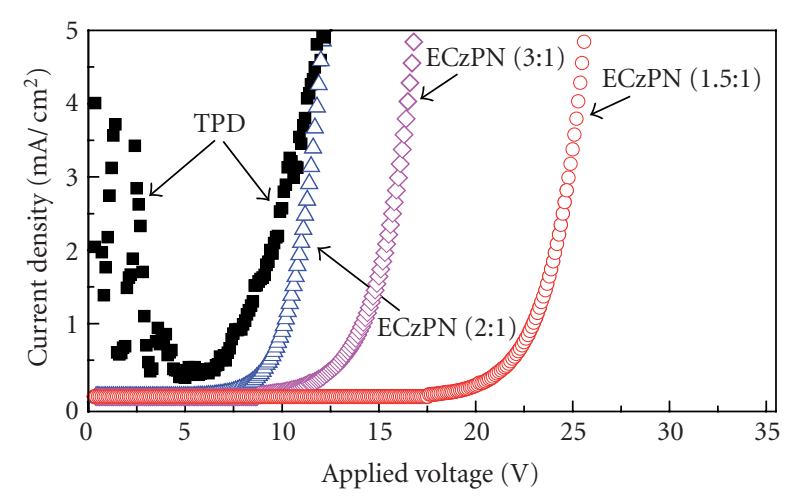

(b)

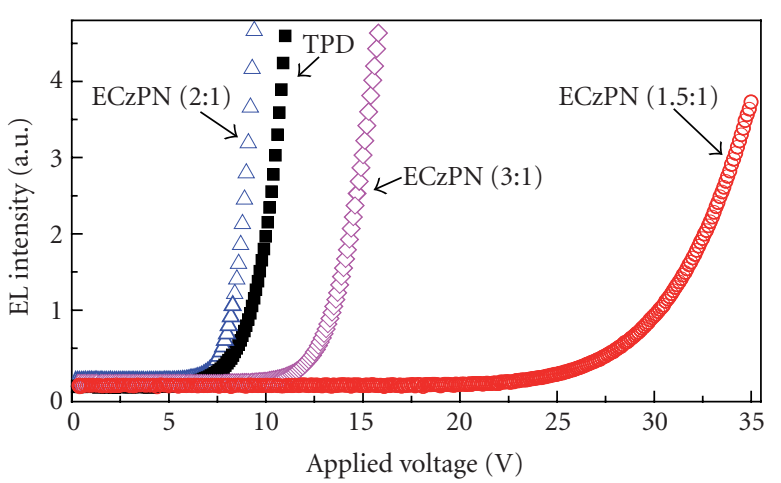

(c)

FIGURE 8: Current density—voltage ((a) full scale; (b) enlarged scale adjusted for the comparison with luminance) and luminancevoltage (c) characteristics of OLEDs made with the ECzPN nanolayers or TPD as a hole injection/transport layer.

Finally, we have tried to correlate the device characteristics with the nanomorphology of ECzPN nanolayers. As shown in Figure 10, the TPD film shows very coarse morphology that features large TPD crystals aggregated each other, indicating a poor film quality which might be responsible for the early degradation of corresponding device at relatively lower current density though the low $\mathrm{Tg}\left(63^{\circ} \mathrm{C}\right)$ of TPD is normally understood as the cause for the poor device 


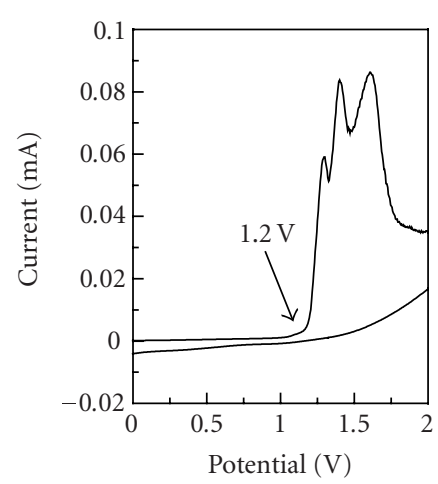

(a)

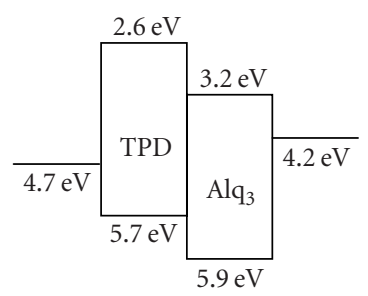

(e)

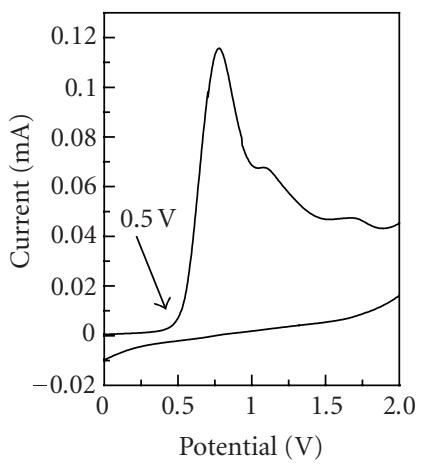

(b)

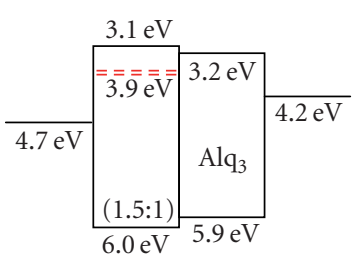

(f)

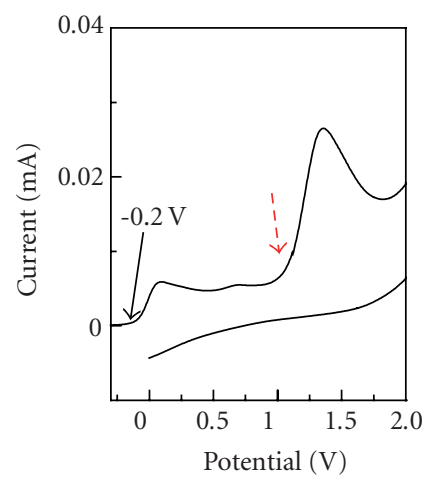

(c)

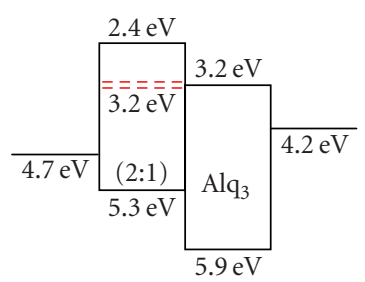

(g)

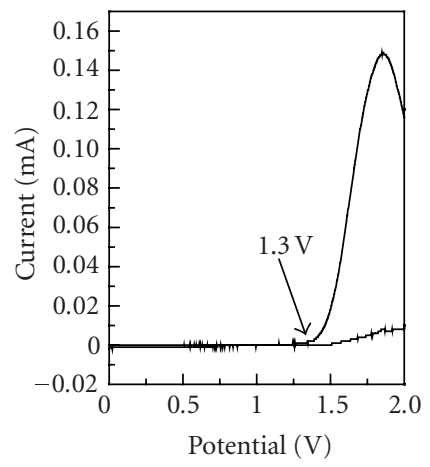

(d)

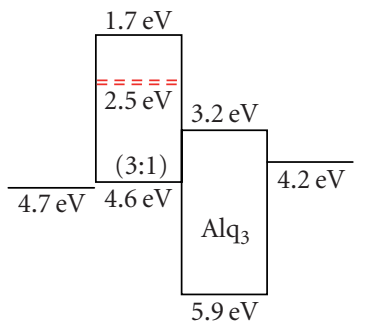

(h)

Figure 9: Cyclic voltammograms for (a) ECzPN (1.5:1), (b) ECzPN (2:1), (c) ECzPN (3:1), and (d) ECN with TPP (1 wt\%): the potential is against $\mathrm{Ag} / \mathrm{Ag}^{+}$. Flat energy band diagrams of OLEDs fabricated in Figure 8, where the hole injection/transport layer is (e) TPD, (f) ECzPN $(1.5: 1),(\mathrm{g}) \mathrm{ECzPN}(2: 1)$, and (h) ECzPN $(3: 1)$. The sub-LUMO band (see dashed red lines) in the middle of HOMO-LUMO levels of each ECzPN nanolayers was calculated on the basis of the ground-state complex band gap $(2.1 \mathrm{eV})$ as shown in Figure 6.

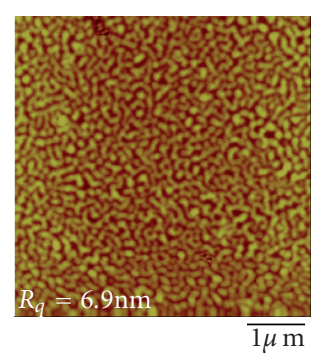

(a)
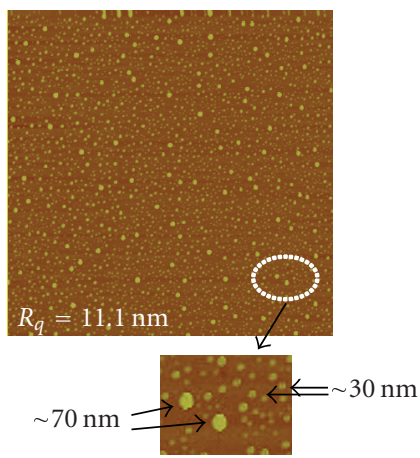

(b)
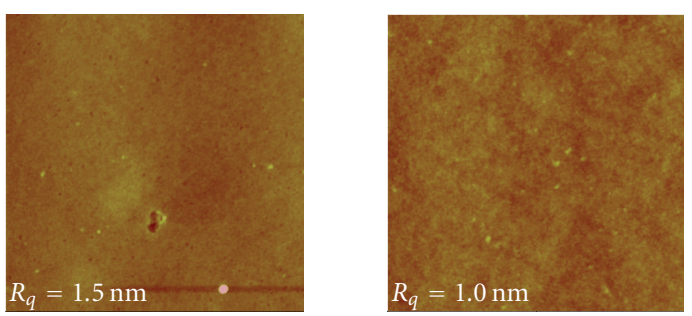

(c) (d)

Figure 10: AFM images (scan size $=5 \mu \mathrm{m} \times 5 \mu \mathrm{m}$ ) of (a) TPD, (b) ECzPN (1.5:1), (c) ECzPN (2:1), and (d) ECzPN (3:1). “Rq” denotes the root-mean-squared roughness of nanolayer surfaces. Note that the enlarged image of (b) shows two kinds of nanoparticles in a size of about $70 \mathrm{~nm}$ and $30 \mathrm{~nm}$.

stability [3]. In contrast, the ECzPN (1.5:1) nanolayer shows a phase-segregated coarse nanomorphology in which two kinds of nanoparticles ( $70 \mathrm{~nm}$ and $30 \mathrm{~nm}$ ) are evenly dispersed over the entire surface of nanolayers: these nanoparticles are considered as the unreacted $\mathrm{DACz}$ molecules remained after the curing reaction and contributed the worst surface roughness $(11.1 \mathrm{~nm})$ amongst all films investigated here. This coarse nanomophology might be more or less re- sponsible for the poor device performance (poor correlation between luminance and current density), even though the major reason is ascribed to the large hole-injection barrier and electron-leakage pathways (sub-LUMO band) due to the ground-state complex formation as discussed in Figure 9. However, no detectable phase segregation was observed for the $(2: 1)$ and $(3: 1)$ nanolayers, indicating almost perfect participation of DACz molecules in the curing reaction. 


\section{CONCLUSION}

The epoxy-carbazole polymeric network (ECzPN) nanolayers were prepared and applied as a hole injection/transport layer for OLEDs. These nanolayers showed fairly good stability against thermal degradation. In particular, a groundstate complex was observed for the cross-linked (reacted) $\mathrm{ECzPN}$ nanolayers by optical measurements, which is considered to affect the significant shift in the HOMO levels of corresponding films. The OLED with the ECzPN $(2: 1)$ nanolayer exhibited almost the similar performance to the TPD device, which is attributed to the shifted HOMO level by the specific interaction (hydrogen bonding) between carbazole and ring-opened epoxy moieties. However, the nanoparticle-contained nanomorphology in the ECzPN (1.5: 1) nanolayer needs further studies to confirm whether it contributes to the device performance badly or not.

\section{ACKNOWLEDGMENTS}

This work was financially supported by the National Research Laboratory Program, Korea, the BK 21 Project, and the SRC/ERC of MOST/KOSEF Program (Grant no. R112000-070-080020). Youngkoo Kim personally thanks Professor Donal D. C. Bradley for financial support for research and living in London.

\section{REFERENCES}

[1] L. S. Hung and C. H. Chen, "Recent progress of molecular organic electroluminescent materials and devices," Materials Science and Engineering: R: Reports, vol. 39, no. 5-6, pp. 143-222, 2002.

[2] Y. Kim, D. K. Choi, H. Lim, and C.-S. Ha, "Accelerated preoxidation method for healing progressive electrical short in organic light-emitting devices," Applied Physics Letters, vol. 82, no. 14, pp. 2200-2202, 2003.

[3] Y. Kim, J. Keum, J.-G Lee, H. Lim, and C.-S. Ha, "Non-linear charge conduction and emission behaviour of OELD fabricated with Alq3 and TPD-doped soluble polyimide," Advanced Materials for Optics and Electronics, vol. 10, no. 6, pp. 273-283, 2000.

[4] C.-M. Bouche, P. Berdague, H. Facoetti, P. Robin, P. Le Barny, and M. Schott, "Side-chain electroluminescent polymers," Synthetic Metals, vol. 81, no. 2-3, pp. 191-195, 1996.

[5] E. Bellmann, S. E. Shaheen, R. H. Grubbs, S. R. Marder, B. Kippelen, and N. Peyghambarian, "Organic two-layer lightemitting diodes based on high- $T_{g}$ hole-transporting polymers with different redox potentials," Chemistry of Materials, vol. 11, no. 2, pp. 399-407, 1999.

[6] A. Kraft, P. L. Burn, A. B. Holmes, D. D. C. Bradley, R. H. Friend, and J. H. F. Martens, "Hole-transporting compounds for multi-layer polymer light-emitting diodes," Synthetic Metals, vol. 57, no. 1, pp. 4163-4167, 1993.

[7] A. Yamamori, C. Adachi, T. Koyama, and Y. Taniguchi, "Electroluminescence of organic light emitting diodes with a thick hole transport layer composed of a triphenylamine based polymer doped with an antimonium compound," Journal of Applied Physics, vol. 86, no. 8, pp. 4369-4376, 1999.
[8] D. B. Roitman, H. Antoniadis, M. Hueschen, R. Moon, and J. R. Sheats, "Polymer thermosetting organic light-emitting devices," IEEE Journal of Selected Topics in Quantum Electronics, vol. 4, no. 1, pp. 58-66, 1998.

[9] D. Müller, M. Gross, K. Meerholz, et al., "Novel cross-linkable hole-transport monomer for use in organic light emitting diodes," Synthetic Metals, vol. 111-112, pp. 31-34, 2000.

[10] T. D. de Morais, F. Chaput, K. Lahlil, and J.-P. Boilot, "Hybrid organic-inorganic light-emitting diodes," Advanced Materials, vol. 11, no. 2, pp. 107-112, 1999.

[11] H. Suzuki and S. Hoshino, "Behavior of charge carriers and excitons in multilayer organic light-emitting diodes made from a polysilane polymer as monitored with electroluminescence," Journal of Applied Physics, vol. 79, no. 2, pp. 858-865, 1996.

[12] Y. Kim, K. H. Bae, Y. Y. Jeong, D. K. Choi, and C.-S. Ha, "An electronically active molecularly doped polyimide hole injection layer for an efficient hybrid organic light-emitting device," Chemistry of Materials, vol. 16, no. 24, pp. 5051-5057, 2004.

[13] Y. Kim, K. Han, and C.-S. Ha, "Synthesis and characteristics of poly $\left[N, N^{\prime}\right.$-diphenyl- $N, N^{\prime}$-bis(4-aminobiphenyl)$\left(1,1^{\prime}\right.$-biphenyl)- $4,4^{\prime}$-diamine pyromellitimide] as a hole injecting and transporting layer for hybrid organic lightemitting device," Macromolecules, vol. 35, no. 23, pp. 87598767, 2002.

[14] Y. Kim and C.-S. Ha, "Semiconducting polyimide nanolayers for organic nanoelectronics: the first applications to hybrid organic light-emitting devices," in Nanotechnology at The Leading Edge, E. V. Dirote, Ed., Nova Science, New York, NY, USA, 2006.

[15] J. Keum, Y. Kim, and C.-S. Ha, "Molecularly doped polymeric network nanolayers for organic light-emitting devices," Macromolecular Research, vol. 14, no. 4, pp. 401-403, 2006.

[16] D. B. Romero, M. Schaer, L. Zuppiroli, M. Leclerc, D. Adès, and A. Siove, "The role of carbazole in organic light-emitting devices," Synthetic Metals, vol. 80, no. 3, pp. 271-277, 1996.

[17] J. Wagner, J. Pielichowski, A. Hinsch, et al., "New carbazolebased polymers for dye solar cells with hole-conducting polymer," Synthetic Metals, vol. 146, no. 2, pp. 159-165, 2004.

[18] E. Mandowska, W. Mazela, P. Czub, A. Mandowski, J. Pielichowski, and J. Swiatek, "Luminescence properties of epoxy resins modified with a carbazole derivative," Macromolecular Symposia, vol. 212, no. 1, pp. 269-274, 2004.

[19] J. Pommerehne, H. Vestweber, W. Guss, et al., "Efficient two layer leds on a polymer blend basis," Advanced Materials, vol. 7, no. 6, pp. 551-554, 1995. 

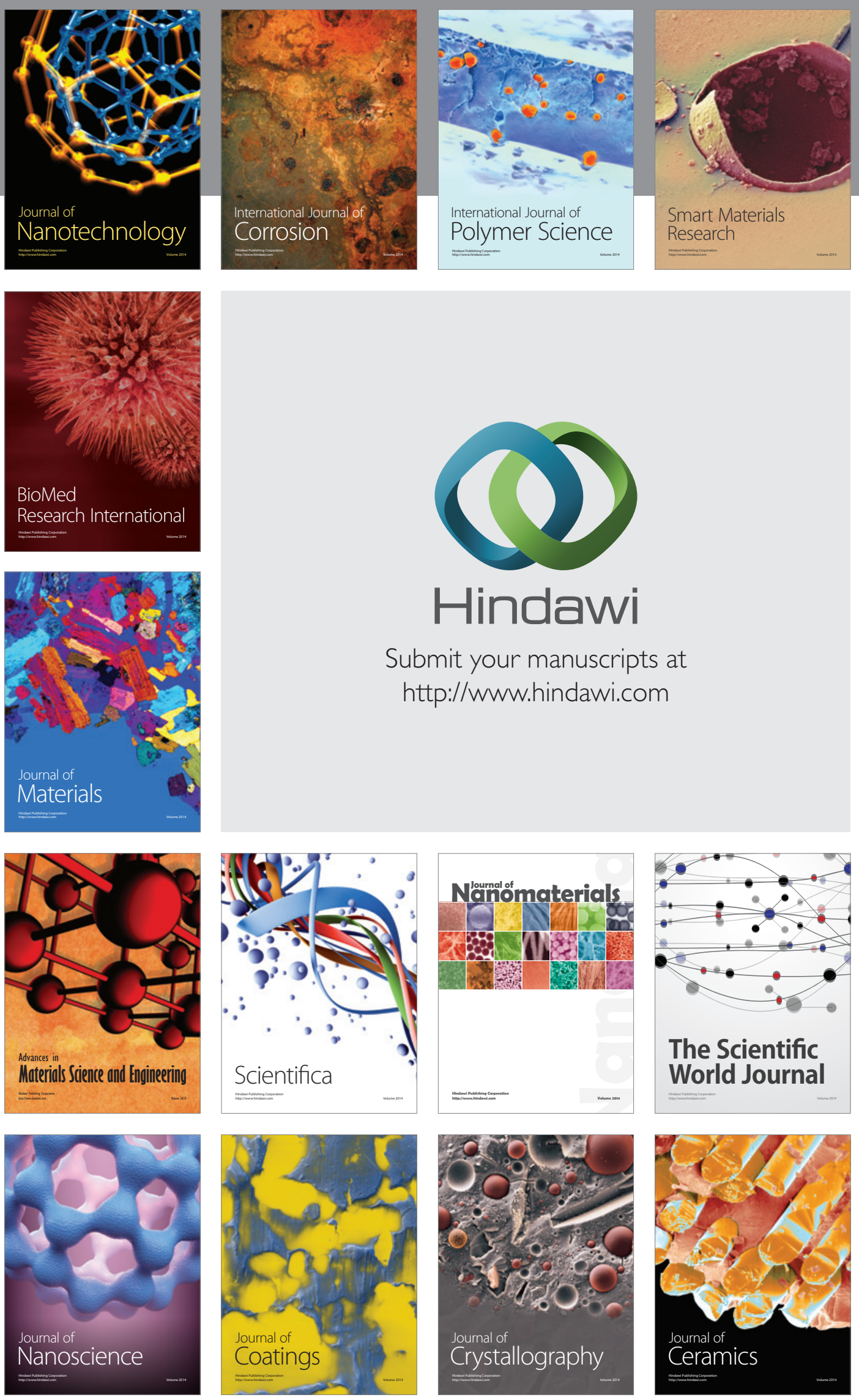

The Scientific World Journal

Submit your manuscripts at

http://www.hindawi.com

\section{World Journal}

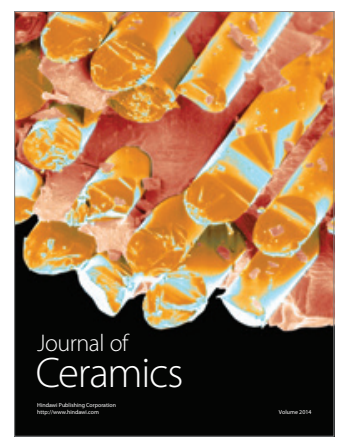

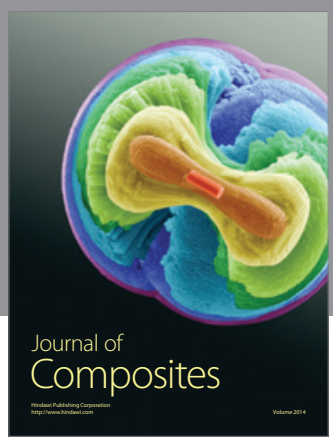
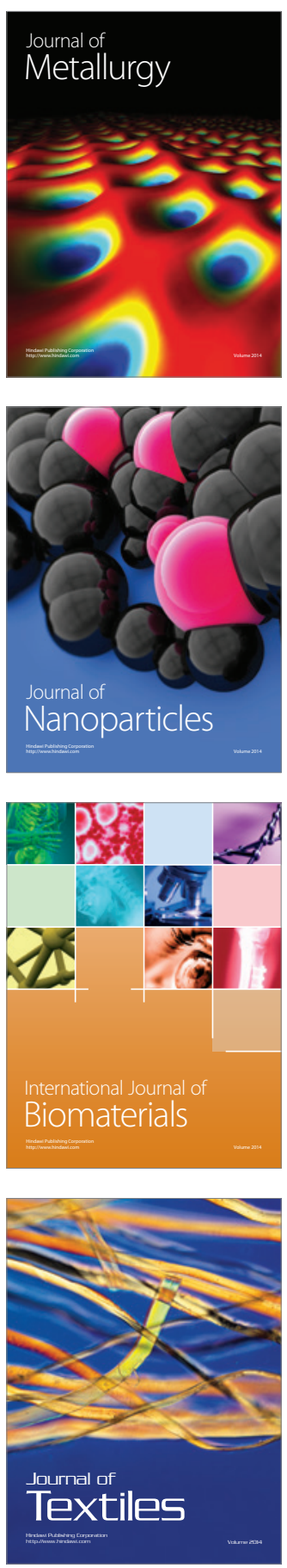